\title{
Electricity Power Insecurity and SMEs Growth: A Case Study of the Cold Store Operators in the Asafo Market Area of the Kumasi Metro in Ghana
}

\author{
Solomon Kwarteng Forkuoh*, Yao Li \\ School of Management \& Economics, University of Electronic Science \& Technology of China (UESTC), Chengdu, \\ China \\ Email: forkuoh6@hotmail.com
}

Received 7 July 2015; accepted 24 July 2015; published 27 July 2015

Copyright (C) 2015 by authors and Scientific Research Publishing Inc.

This work is licensed under the Creative Commons Attribution International License (CC BY). http://creativecommons.org/licenses/by/4.0/

(c) (9) Open Access

\section{Abstract}

The poor quality electricity supply has been recorded as a major problem hampering the operations of SMEs in developing countries, and is more prevalence in Sub-Saharan African countries and some part of the Middle-East. In recent times, access to reliable electricity supply and associated high tariffs is creeping to the top spot of SMEs challenges in Ghana, with SMEs in the country losing over US $\$ 686.4$ million sales annually since the beginning of 2009 . Considering the significant contributions SMEs made towards the socio-economy of countries, if care is not taken to assess the effect of the intermittent power outages on the running of businesses so as to create the awareness to policy formulators in other to find a lasting solution to this canker, then, the demise rate of SMEs will be on the higher pedestal. Against this backdrop, the researchers assess the impact of the power insecurity on the growth of SMEs with a particular study on cold-store operators in Asafo Market of Kumasi in Ghana, since previous researchers have not zoom on small sectors and also did not used case study approach. The research findings indicated that, power outages had a negative effect on SMEs growth, while the cost of operating businesses saw a significant increase under the power outages. Cost of alternative sources of power also significantly pushes the operation cost of businesses high.

\section{Keywords}

Electricity Outages, SMEs Growth, Ghana, Challenges

\footnotetext{
${ }^{*}$ Corresponding author.
}

How to cite this paper: Forkuoh, S.K. and Li, Y. (2015) Electricity Power Insecurity and SMEs Growth: A Case Study of the Cold Store Operators in the Asafo Market Area of the Kumasi Metro in Ghana. Open Journal of Business and Management, 3, 312-325. http://dx.doi.org/10.4236/ojbm.2015.33031 


\section{Introduction}

Access to electricity and its accompanied high tariffs poses a greater challenge to SMEs growth in lower income countries, as compared with those in higher income countries.

This assertion is confirmed in a research by [1] which reveals that, the proportion of SMEs in high-income countries (HICs) citing electricity as a major constraint is half of their counterparts in the Sub-Saharan African and Asia countries. Cost and time spent on acquiring electricity were also higher in the Less Developed Countries compared with that of High-Income Countries (HICs). The study went on to establish that the absence of reliable electricity supply to most SMEs in low income countries and its high tariffs to SMEs was becoming the number one challenge to SMEs in most developing countries [1].

Research by [2] on the effect of electricity power outage on SMEs in Ghana posited that, the current electricity crises in the country were costing the SMEs over US \$686.4 million of annual sales. Based on previous research finding using a population of over 4 million SMEs in Ghana with a sample size 1250, micro businesses were the most affected by the electricity problems, recording a loss of around UD \$2.2 Million daily, which represented over $50 \%$ of their daily sales.

These have been partly blamed on market and state failures, which have led to the poor electricity supply.

Similar research by [3] on the effect of poor electricity supply on SMEs growth in Ghana, established that, the absence of reliable electricity supply and its compounded high tariffs was having a negative impact on the quantity and quality of produce which had led to poor sales and low profitability. As was earlier indicated by [4], lack of finance and unstable electricity supply was the most severe obstacles to SME growth in developing countries.

A previous research on the obstacles to SMEs growth and development in the Sub-Saharan African countries, [5]-[7], emphasized that, weakly financial markets and unreliable electricity supply were the most obstacles to SMEs growth. These findings show that, the electricity problems have been with the SMEs in developing countries for a longer period. Also the study by [8] on the issue of electricity supply and SMEs growth in the Sub-Saharan African countries, indicated that, inadequate electricity supply and its attained high tariffs acted as an impediments to business operations and also increased the cost of operations, forcing some SMEs into complete oblivion.

In an attempt to mitigate the hash effect of the poor power supply on their businesses, some SMEs use alternative power generators, reduce hours of work, and vary the working hours [2]; ironically, these measures increase the operational cost of the business as is reported that on average, 86\% of SMEs in Nigeria use generator compared with $21 \%$ in Nepal where electricity supply is a bit stable [1].

The absence of competition in the electricity supply business in Ghana has been blamed as a possible cause of poor performance by the state-owned Electricity Company of Ghana (ECG). [9] is of the view that, the monopoly power enjoyed by the ECG has led to price hicks and poor quality of service delivery which in the long run affects consumers negatively. Secondly, the interests of the general public, especially those who rely significantly on electricity, will be put to risk through price hikes and "degradation of quality of supply and customer service” [9]. As it has also been established by [2], the Electricity Company of Ghana (ECG) is over protected and pampered, which has led to inefficiency and waste in the service delivery.

Considering the important role electricity plays in the running and growth of these SMEs (Cold Store Operators), and the fact that there are no prudent alternatives [10], as firms need electricity for operation processes including storage and production. There is therefore a need to study into this canker to find a lasting solution to it.

A study on the effect of power fluctuation on the profitability and competiveness of SMEs is therefore crucial and a necessary step to influence government action on energy supply.

This research aims at assessing the effect of electricity power insecurity on the growth of SMEs (Cold Store Operators), its accompanied cost implications, and the available alternative power supply. In the end, a suitable solution to the crises will be recommended.

The study will also add to the existing limited literature in the sector, since the electricity crises in Ghana are an on-going phenomenon. The research is organized and presented in four sections, the theoretical background, methodology, research finding and conclusions.

\section{Theoretical Section}

\subsection{Electricity Outages and SMEs Growth}

SMEs growth is the wish of both the entrepreneurs and the State, because of the important role SMEs play in the 
economic development of the individual and the nation at large [11], as a result, efforts are geared towards the growth of SMEs from several angles, yet challenges and other factors usually result in stunted growth and early demise of SMEs.

A positive correlation has been established by several researchers [12] [13] between electricity infrastructure usage by firms and higher growth in firm's productivity and the economy. Hence poor and interrupted electricity supply and its accompanied high tariff leads to lower performance and productivity [14]. In explanation on the existence of output variations of firms in different countries, [15] found that, the existence of reliable electricity infrastructure plays a significant role in firms growth and development disparities.

There is an ample evidence that, poor and high tariff electricity supply affects the growth of firms negatively [16], empirically, the on-going electricity power load shedding exercise in Ghana, has led to several companies laying off its employees, with even the country's largest commercial bank GCB retrenching almost quarter of its working force, all because businesses are slow [17]. In 2009, similar electricity challenges in Tanzania, led to the laying off several employees both in the public and private sectors [18]. In measuring the effect of external environment on the growth of firms, [14] established that, poor electricity supply has negative effect on firm's growth. All because most firms rely on electricity for production and cannot substitute it cheaply [19], as research by [3], on the effect of the electricity outages on the operations of businesses in Ghana, posited that, SMEs are unable to improve on both quantity and quality of their produce, leading to low profit and negative Return on Assets and Investment, this implies that, firms with higher access to electricity tend to have a higher productivity than those without or with poor power supply [2].

When it come to the size of the firm and the impact of electricity outages on productivity, research indicate that small firms are the hardest hit than their larger counterparts, whiles the shorter reoccurrences of outages have hasher impact than longer durations [20], this implies that, the situation in Ghana now is terrible, since the electricity load shedding is hourly and irregular, given the smaller firms limited chance to plan and operate [2].

Some researchers are of the view that poor electricity supply generally may not always impact negatively on firms output, as a study by [14], revealed a positive impact of electricity outages on some selected manufacturing firms in Senegal. The researchers attributed this trend to proper management and over reliance on electricity during those periods.

Notwithstanding those findings, electricity outages have been proven severally as having negative effect on firms' productivity, especially in Africa and among small firms whose activities hinges around the availability of electricity power [21] and therefore support the conclusion that, reliable supply of electricity translate into higher performance of the SMEs, hence efforts should be geared towards the provision of reliable electricity [22].

Based on the above literatures reviewed, the researcher proposes a hypothesis that H1: Electricity power outages affects the growth of SMEs negatively.

\subsection{Electricity Outages and SMEs Cost of Operations}

The cost of electricity supply is higher in most developing countries than in developed ones, whiles there are also fewer and costly alternative energy supply in developing countries [11]. Research by [1] shows a positive correlation between electricity outages and high cost of SMEs operations. This has been attributed to the fact that, most SMEs have financial difficulties and may not afford the high cost alternative energy supply, as a result, may employ production cutting tactics, leading short fall in sales, profit but high production cost from the fixed cost components [3]. The high cost of operations may also stem from the damages to equipment such as, refrigerators, air conditioners and other valuable machineries [1] [2]. From the point of view of [23], that, electricity outages brings high cost of product and low labor productivity to SMEs, even though determining the actual cost may be difficult.

Empirical research by [24] on the effect of electricity power outages on the growth and survival of firms in Nigeria, established that, between 2000 and 2008 around 820 manufacturing firms were closed down, with the figure moving up to 834 in the following year, all because of poor electricity power supply and high cost on the alternative energy supply. [25], is also of the view that, electricity power outages have positive impact on the rise in operational of SMEs.

We therefore propose a hypothesis based on the literatures reviewed that $\mathrm{H2}$ : Electricity power outages increases the cost of operating SMEs. 


\subsection{Alternative Power Supply and Cost Implications to SMEs}

Report by [26] on the availability, cost and usage of alternative energy source besides electricity indicates that, countries in the Sub-Saharan Africa, have not been able to take advantages in tapping energy from alternative sources such as solar, wind and water bodies, as a result they over rely on little hydro-electric power generation, which most cases uses old technology resulting in inefficiencies. The report went further to say that, only $26 \%$ of households in Africa have access to electricity, making Africa the lowest electricity access in the world. In dealing with the high tariffs and poor electricity supply, SMEs in Indian manufacturing industries switch from high energy consumption industries to less electricity-intensive production processes [27]. This may not be applicable to all, since some businesses procedures cannot be changed over-night. The [28] reported that, the cost and the time involve in acquiring electricity in developing countries are far difficult comparing with that of the developed countries.

Report by [29] on the alternative usage of energy in China, shows that, SMEs turn to cut down cost on electricity by increasing cost on material through outsourcing of intermediate products rather than starting the production from the scratch.

In Ghana, some of the cold store operators have adopted to drying and smoking of their fish and meat product as a means of preserving them, but the demand for the type is low and very tedious to practice [2].

The use of generators as alternative source of electricity is very popular among African SMEs than most regions in the world [30], as [31], put it, that with poor electricity supply, turns to rely heavily on diesel powered generators, though they use for limited hours and as and when needed bases.

Research by [32] on the use of generators in Nigeria by the SMEs during power outages, established that, generator usages have now been accepted as part of SMEs overhead cost, as a result higher percentage of SMEs there, use it.

From the literatures above, the ensuing hypothesis have been proposed H3: Alternative energy supply has higher cost implications on SMEs operations.

H4: high cost of alternative power supply positively affect the operational cost of SMEs.

H5: High operational cost has negative impact on the SMEs growth.

(POEXP-POWER OUTAGES EXPERIENCE, HCAPS-HIGH COST OF ALTERNATIVE POWER, HOCOST-HIGH OPERATIONAL COST.)

Figure 1 below illustrates the hypothesis to be tested and followed in this research work.

\section{Methodology}

The terms of reference for the study was the fish and meat sellers using refrigerators in storing their products within the Asafo market (noted for cold store businesses) since the most significant impact of the electricity outages on SMEs will be much felt in that area since the business survival thrives of electricity.

The study adopted the National Board for Small Scale Industries (NBSSI) of Ghana's definition of SMEs, for those employing below 250 workers with capital less than US \$100,000 [33].

This research used both qualitative and quantitative approach in obtaining the right data (primary and secondary) for the analysis. A total of 450 cold store operators within the Asafo Market catchment area whose business depends heavily on the electricity supply was select for the study. The sample size was influenced by the population of the cold store operators in the cluster and some common characteristics they exhibited during the

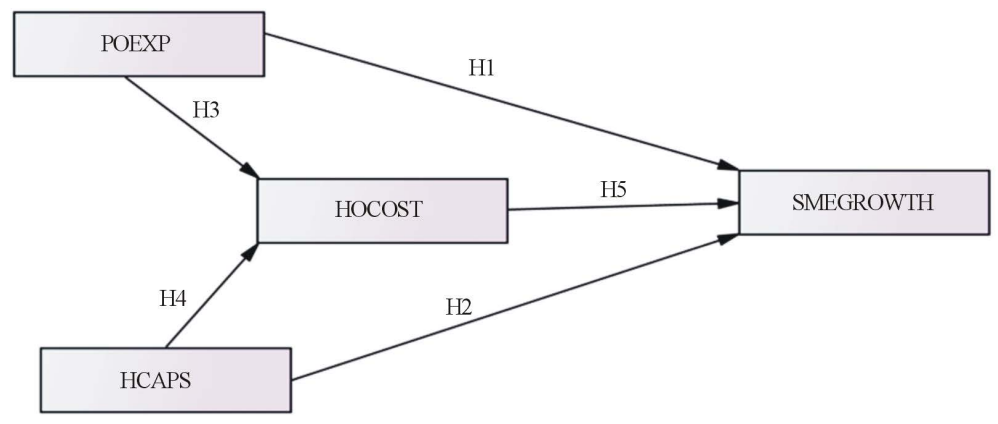

Figure 1. The effect of power outages on SMEs growth. 
pre-survey exercise.

A purposive sampling techniques was employed in the selection process, since the major targets were those severely affected by the electricity outages. So the area was imaginary divided into four and 60 sample from each group was selected with additional 10 from their union executives. A stratified sampling techniques was used. Because the traders were desperately looking for a solution to the problem, they were willing to give all the needed information, as a result, the researcher was able to retrieve 250 questionnaires from the total questionnaires administered.

The dependent variable is the growth of the SMEs, whiles the independent are power outages experience high cost of alternative power, and high operational cost (the sample questionnaire is attached as Appendix for reference).

The quantitative data obtained was put through several stages such as, data cleaning, normality test, linearity test, EFA, CFA and Structural Equation Model was used in estimating paths coefficients and significant levels whilst Alpha Cronbach's, discriminant and convergent validity estimate were generated to validate the measurement model.

SPSS version 21 was used in analyzing the data using the SEM to establish the relationships and associations between the dependents and independents variables proposed in this study.

\subsection{Data Analysis and Presentation}

Purposively, 250 questionnaires were sent to selected SMEs located in Ghana with 250 questionnaires repressenting $100 \%$ approximately retrieved, involving 124 respondents as females and 126 as males, 131 with ages of 30 years and above and 119 with ages of 30 years and below, 156 as married and 94 as single. Also, 145 of the respondents have experienced formal education and 105 have none of educational experience.

To ensure sufficient usability, reliability, and validity of the data received for further analysis in testing causal relationships formulated in this study, the data was staged in multiples of screening. In Microsoft excel, the compute blank values for all the cases showed values not equal to zero and that none of the cases had missing value to be either eliminated or replaced with the mean. Subsequently, unengaged responses were checked in the data set to establish more decent analysis. This represent cases that respondents answered with either same values (e.g. 3333, 1234 or 1111, 2222, 3333, etc.) in the Likert scale for survey item for all the constructs. Explicitly, this implies that, the research respondents were not engaged in providing indebt views or explained no reasonable variance among constructs in the data to support the causal specifications proposed in the research model. In identification of such cases, standard deviation was computed for individual cases received using excel and given the threshold of SD > 0.5, all cases with SDs less than the threshold were eliminated as the amount of variance explained among the items in such cases are not highly strong enough to predict the effect of one construct on the other (IVs and DV). None of the cases had discrepancies as the SD were all sufficiently greater than 0.5 and that, all the cases were considered sufficient for further analysis. In expedition for more accurate and reliable data set, the distribution, location and variability of the data as responded by the 250 selected sample was verified. Guided by kurtosis, none of the values was greater than or less than $+/-2.00$ to be considered an indication for potentially problematic kurtosis, hence incidence of insufficient variance were present in the data set. Successively, multivariate assumption was clarified in the data set. Testing the linear assumptions established in the research model, is the linearity and multi-collinearity tests that exposes the linear concepts in the model to predict the existence of multi-collinearity issues among constructs specified in the model. In Linearity test, curve estimation regression was computed for all direct effects or linear relationships in the model. The results show that the relationships between variables are sufficiently linear with all p-values less than 0.05 and F-value for all linear relationships among variables higher than other curves estimates. Regarding Multi-collinearity the Variable Inflation Factor (VIF) for all the independent variables were simultaneously tested. Given the outcome, the VIFs were all less than 2.0, indicating that all the variables are distinct and are of less or no issues of multi-collinearity problem.

\subsection{Exploratory Factor Analysis (EFA)}

From the cleaned field data, the EFA using PCA with Varimax rotation was executed to ascertain the correlations postulated in the model. Several analysis were staged to substantiate the expected loadings of the observed variables and the existence of adequate correlation whilst reliability and validity criteria are all met. The KMO 
value obtained (0.872) with approximate Chi-Square of 6286.52 at $210 \mathrm{DF}$, significant at 0.001 level depict that, the correlations in the items of all the constructs are sufficiently large for the PCA. Indeed, significant Bartlett's test demonstrates that, the inter-correlations in the data set is not from a population in which the correlation is an identity matrix and that, items correlation coefficients different from zero. This is further ascertained by the individual KMO values obtained for each items which were all above 0.5 indicating good sampling adequacy for the research data. Prior to the initial extraction is the factor eigenvalues above 1 as recommended by Kaiser (Kaiser, 1960). The percentage (\%) of variance explained by each linear component evinces that, the POEXP factor explains approximately $24.8 \%$ of the total variance with 5.2 eigenvalue, the HOCOST factor of $20.6 \%$ with 4.3 eigenvalue, the HCAPS factor of $20.6 \%$ with 4.3 eigenvalue, and the SMEGROWTH factor of $18.7 \%$ with 3.9 eigenvalue. The factor loadings present the correlations of each item with the factors extracted. Explicitly, the observed values for the factor loadings explains that, all the items are highly related to the factors on which they are extracted. Regarding the total proportion of variance in the variable explained in all the constructs by the four factors, is simply the sum of the squared factor loadings which is known as the communality of the variables. In the section labeled Communalities, the values obtained shows that, the four factors are sufficiently defined by the items correlating with them. Communalities ranging from 0.686 to 0.962 explained that, none of the observed variables were out of prediction from the four factors extracted. Table 1 depicts the initial factor extraction.

The rotated component matrix (factor loading) depicts the correlation of each item with each factor. The items designed for the SMEGROTH variable show a correlation coefficients from 0.884 to 0.977 with internal consistency reliability coefficient of 0.969 , the items for HCAPS variable correlate from 0.914 to 0.943 with Cronbach's alpha value of 0.962 , the items for HOCOST variable's correlation coefficients ranges from 0.908 to 0.952 with reliability alpha of 0.960 and the items for the POEXP variable possess correlation coefficients ranging from 0.816 to 0.944 with a reliability coefficient of 0.931 . Given these correlation coefficients and the alpha reliability ratios, all the items are sufficiently correlated with their factors and also internally consistent in obtaining survey data for the study. The factor pattern is clearly defined with no cross loadings meaning the factor structure has no concerns of discriminant validity issues. Table 2 shows the rotated factor structure and Cronbach's alpha coefficients for the components extracted.

\subsection{Confirmatory Factor Analysis}

Subsequent to the EFA was the Confirmatory Factor Analysis which was conducted to obtain a decent measurement model for the study, utilizing the pattern matrix model builder of the SPSS Amos version. The CFA was computed to reinforce and confirm the factor structure specified in the EFA analysis in view to clarify the relationship between observed measures (indicators) and the latent variables. In confirmation, the modification indices generated examine the predictive ability of the measurement constructs. The generated Chi-square of 412.976 at $183 \mathrm{df}$ is statistically significant at the 0.001 level, meaning, the specified measurement model has less or no discrepancies in predicting the latent variables. All the path estimates were sufficiently higher than 0.5 (as shown in Figure 1) which goes to fortify the values obtained for the fit indices as indicated in Table 3 and also graphically shown as Figure 2.

\subsection{Validating the Measurement Model}

To further establish reliable and valid measurement model, convergent validity with AVE was calculated whilst the square root of the AVE (on the diagonal in the matrix below) were compared to all inter-factor correlations. The results as shown in Table 4 indicate that, all factors obtained decent AVE values above 0.50 and all the diagonal values are greater than the correlations among the factors indicating adequate convergent and discriminant validity of the specified measurement model. Also, both MSV and ASV were far less than the AVE which further confirms valid distinct factors in the model. In addition, the composite reliability (CR) was computed for all factors and in all cases, the CR is highly above the minimum threshold of 0.70 signifying the reliability of the factors in the measurement model.

\subsection{Structural Model}

From the factor scores, composite variables were created in AMOS. As guided by extant theories, direct paths were added among the variables to achieve excellent fit for the construct model to probably indicate that, the 
Table 1. Initial factor extraction.

\begin{tabular}{|c|c|c|c|c|c|}
\hline \multicolumn{5}{|c|}{ Kaiser-Meyer-Olkin measure of sampling adequacy. } & \multirow{2}{*}{\begin{tabular}{|c|}
0.872 \\
6286.52 \\
\end{tabular}} \\
\hline \multicolumn{5}{|c|}{ Approx. chi-square } & \\
\hline Bartlett's test of sphericity & \multicolumn{3}{|c|}{$D F$} & & 210 \\
\hline \multicolumn{5}{|c|}{ SIG. } & $\mathbf{0}$ \\
\hline Constructs \& items & Items KMO & Factor loadings & Eigenvalues & $\%$ of variance & Communalities \\
\hline POEXP & & & 5.215 & 24.835 & \\
\hline Q1 & $0.782^{\mathrm{a}}$ & 0.888 & & & 0.793 \\
\hline Q2 & $0.862^{\mathrm{a}}$ & 0.859 & & & 0.739 \\
\hline Q3 & $0.872^{\mathrm{a}}$ & 0.816 & & & 0.686 \\
\hline Q4 & $0.830^{\mathrm{a}}$ & 0.907 & & & 0.824 \\
\hline Q5 & $0.805^{\mathrm{a}}$ & 0.944 & & & 0.895 \\
\hline HOCOST & & & 4.345 & 20.691 & \\
\hline Q6 & $0.932^{\mathrm{a}}$ & 0.908 & & & 0.827 \\
\hline Q7 & $0.843^{\mathrm{a}}$ & 0.911 & & & 0.838 \\
\hline Q8 & $0.872^{\mathrm{a}}$ & 0.931 & & & 0.87 \\
\hline Q9 & $0.880^{\mathrm{a}}$ & 0.952 & & & 0.91 \\
\hline Q10 & $0.898^{\mathrm{a}}$ & 0.934 & & & 0.875 \\
\hline HCAPS & & & 4.328 & 20.611 & \\
\hline Q11 & $0.786^{\mathrm{a}}$ & 0.914 & & & 0.837 \\
\hline Q12 & $0.902^{\mathrm{a}}$ & 0.931 & & & 0.868 \\
\hline Q13 & $0.877^{\mathrm{a}}$ & 0.924 & & & 0.86 \\
\hline Q14 & $0.824^{\mathrm{a}}$ & 0.942 & & & 0.89 \\
\hline Q15 & $0.903^{\mathrm{a}}$ & 0.943 & & & 0.891 \\
\hline SMEGROWTH & & & 3.942 & 18.773 & \\
\hline Q16 & $0.927^{\mathrm{a}}$ & 0.902 & & & 0.82 \\
\hline Q17 & $0.921^{\mathrm{a}}$ & 0.884 & & & 0.783 \\
\hline Q18 & $0.833^{\mathrm{a}}$ & 0.977 & & & 0.962 \\
\hline Q19 & $0.878^{\mathrm{a}}$ & 0.969 & & & 0.945 \\
\hline Q20 & $0.914^{\mathrm{a}}$ & 0.944 & & & 0.894 \\
\hline Q21 & $0.950^{\mathrm{a}}$ & 0.902 & & & 0.822 \\
\hline
\end{tabular}

Source: field data.

hypothesized relationships exist through linear relationships among constructs. The goodness of fit indices indicate adequate fit for the construct model at 0.672 probability of 0.179 Chi-square at $1 \mathrm{df}$ as shown in Table 5 .

\subsection{Relationship Testing}

In testing the research hypotheses, standardized path estimates were computed for all the specified direct paths. By inspection, all the estimates both direct and indirect relationships between the predictor variables and the 


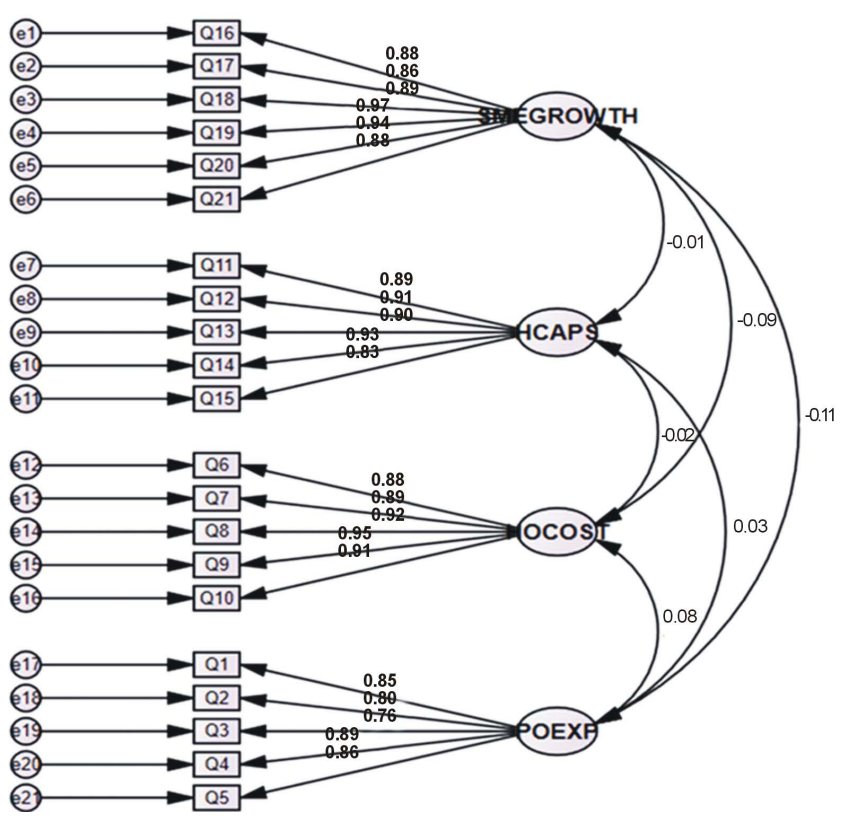

Figure 2. Measurement model.

Table 2. Rotated component matrix and alpha reliability coefficients.

\begin{tabular}{|c|c|c|c|c|}
\hline \multirow{2}{*}{ Items } & \multicolumn{4}{|c|}{ Component } \\
\hline & SMEGROTH (F1) & HCAPS (F2) & HOCOST (F3) & POEXP (F4) \\
\hline Chrombach's alpha & 0.969 & 0.962 & 0.960 & 0.931 \\
\hline Q1 & & & & 0.888 \\
\hline Q2 & & & & 0.859 \\
\hline Q3 & & & & 0.816 \\
\hline Q4 & & & & 0.907 \\
\hline Q5 & & & & 0.944 \\
\hline Q6 & & & 0.908 & \\
\hline Q7 & & & 0.911 & \\
\hline Q8 & & & 0.931 & \\
\hline Q9 & & & 0.952 & \\
\hline Q10 & & & 0.934 & \\
\hline Q11 & & 0.914 & & \\
\hline Q12 & & 0.931 & & \\
\hline Q13 & & 0.924 & & \\
\hline Q14 & & 0.942 & & \\
\hline Q15 & & 0.943 & & \\
\hline Q16 & 0.902 & & & \\
\hline Q17 & 0.884 & & & \\
\hline Q18 & 0.977 & & & \\
\hline Q19 & 0.969 & & & \\
\hline Q20 & 0.944 & & & \\
\hline Q21 & 0.902 & & & \\
\hline
\end{tabular}

Extraction method: Principal component analysis. Rotation method: Varimax with Kaiser normalization. ${ }^{\text {a Rotation con- }}$ verged in 5 iterations. 
Table 3. Chi square and goodness of fit.

\begin{tabular}{|c|c|c|}
\hline \multicolumn{3}{|c|}{ Indeces } \\
\hline Chi square & 412.976 & \\
\hline $\mathbf{D} / \mathbf{F}$ & 183 & \\
\hline Probability & 0.000 & \\
\hline \multicolumn{3}{|c|}{ Goodness of fit } \\
\hline Metric & Observe values & Recommended thresholds \\
\hline Cmin/Dif & 2.257 & Between 1 and 3 \\
\hline CFI & 0.963 & $>0.950$ \\
\hline RMSEA & 0.051 & $<0.060$ \\
\hline PCLOSE & 0.331 & $>0.050$ \\
\hline SRMR & 0.072 & $<0.090$ \\
\hline RMR & 0.010 & $<0.05$ \\
\hline PNFI & 0.583 & $>0.50$ \\
\hline GFI & 0.870 & $>0.80$ \\
\hline NFI & 0.936 & $>0.90$ \\
\hline
\end{tabular}

Source: field data.

Table 4. Validity and reliability of the measurement model.

\begin{tabular}{ccccccccc}
\hline & CR & AVE & MSV & ASV & HOCOST & SMEGROWTH & HCAPS & POEXP \\
\hline HOCOST & 0.960 & 0.828 & 0.007 & 0.004 & 0.910 & & & \\
SMEGROWTH & 0.971 & 0.846 & 0.012 & 0.007 & -0.086 & 0.920 & & \\
HCAPS & 0.962 & 0.834 & 0.001 & 0.000 & 0.016 & -0.009 & 0.913 & \\
POEXP & 0.932 & 0.733 & 0.012 & 0.006 & 0.075 & -0.111 & 0.029 & 0.856 \\
\hline
\end{tabular}

Table 5. Chi square and goodness of fit.

\begin{tabular}{|c|c|c|}
\hline \multicolumn{3}{|c|}{ Indeces } \\
\hline Chi square & 0.179 & \\
\hline $\mathbf{D} / \mathbf{F}$ & 1 & \\
\hline Probability & 0.672 & \\
\hline \multicolumn{3}{|c|}{ Goodness of fit } \\
\hline Metric & Observe values & Recommended thresholds \\
\hline CMIN/DIF & 0.179 & Less or between 1 and 3 \\
\hline CFI & 1.00 & $>0.950$ \\
\hline RMSEA & 0.000 & $<0.060$ \\
\hline PCLOSE & 0.756 & $>0.050$ \\
\hline RMR & 0.007 & $<0.05$ \\
\hline PNFI & 0.166 & $>0.50$ \\
\hline GFI & 1.00 & $>0.80$ \\
\hline NFI & 0.998 & $>0.90$ \\
\hline
\end{tabular}

Source: field data. 
criterion variable are significantly different from zero (all p-values $<0.001$ and 0.05 as shown in Table 6 ). In contrast, the POEXP factor is highly and negatively related to SMEs growth with beta of -0.263 , the HCAPS factor is next in predicting significant variability in the SMEs growth with beta of -0.240 whiles the HOCOST factor is the least predictor variable on SMEs growth with beta of -0.193. Also, the effect of POEXP and HCAP on HOCOST factor were significantly different from zero in that the POEXP factor is positively related to SMEGROWTH with 0.146 regression weight whilst the HCAP factor is also positively related to SMEGROWTH with 0.267 regression weight. In all the relationship estimates, the regression weight for POEXP, HCAPS, and HOCOST in the prediction of SMEG is significantly different from zero at the 0.001 level (two-tailed) given that, the probabilities of obtaining critical ratios as large ranging from -4.604 to -3.244 in absolute value is less than 0.001. Regarding the impact of POEXP, HCAPS on HOCOST of Small and Medium Enterprise, there exist positive effect, in that an increase in power outages and increase in cost of alternative power supply considerably increase the cost of SMEs operations (HOCOST). Given these analyses, the alternative hypotheses for all the proposed relationships are accepted, and the path estimates are shown in Figure 3 below.

\section{Research Findings}

The research findings indicated that, power outage experience has a negative impact on SMEs growth, and this is in line with the findings by [3]. This shows that, the current electricity outages experiencing in Ghana, is affecting the growth of SMEs through loss of sales [2]. Also this study has established that, power outages experience increases the operation cost of SMEs, due to the high cost of alternative energy supply and the damages of assets through the power fluctuations. The operational cost in effect also have a damming effect on the growth of the SMEs, since most of the revenue meant for reinvesting will rather goes to the servicing of electricity and alternative power bills.

The research further shows that, the major alternative power supply is generator, but the cost of using the generator was very high and was increasing the operational cost and reducing the firm's growth.

\section{Recommendations}

Considering the significant role play by SMEs and the limitations posed by poor electricity supply on their

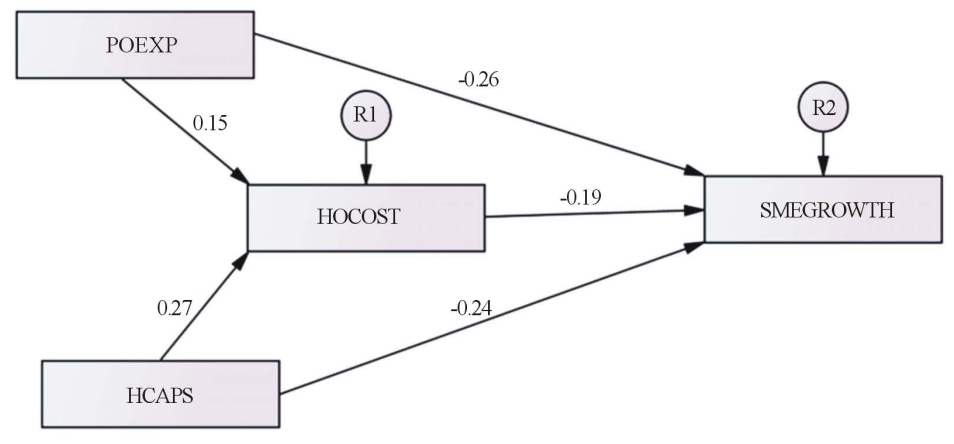

Figure 3. Structural model.

Table 6. Regression coefficients and paths remarks.

\begin{tabular}{|c|c|c|c|c|c|c|c|c|c|}
\hline \multirow{2}{*}{\multicolumn{3}{|c|}{ Paths }} & \multirow{2}{*}{$\begin{array}{c}\text { Unstandardized } \\
\text { Estimate }\end{array}$} & \multicolumn{6}{|l|}{ Standardized } \\
\hline & & & & Estimates & S.E. & C.R. & $\mathrm{P}$ & Label & Remarks \\
\hline HOCOST & $<--$ & HCAPS & 0.262 & 0.267 & 0.059 & 4.419 & $* * *$ & $\mathrm{H} 4$ & Accept \\
\hline HOCOST & $<---$ & POEXP & 0.128 & 0.146 & 0.053 & 2.412 & 0.016 & H3 & Accept \\
\hline SMEGROWTH & $<--$ & POEXP & -0.41 & -0.263 & 0.089 & -4.604 & $* * *$ & H1 & Accept \\
\hline SMEGROWTH & $<---$ & HCAPS & -0.416 & -0.24 & 0.102 & -4.08 & *** & $\mathrm{H} 2$ & Accept \\
\hline SMEGROWTH & $<---$ & HOCOST & -0.34 & -0.193 & 0.105 & -3.244 & 0.001 & H5 & Accept \\
\hline
\end{tabular}


performances, it is not in bad taste to see governments from most developing countries, coming out with policies and programs to mitigate the poor electricity supply [1].

The most obvious area for action is to improve the reliability of the electricity supply, which needs to be measured and monitored. This may require short-term action to reduce technical faults, for example, through maintenance of the transmission and distribution infrastructure, or it may require longer-term interventions to expand generating capacity.

As the case in Ghana, proper load shedding exercise for equitable distribution and future planning by SMEs are also encouraged as a short term remedy, for the long term solution, [2] suggested that, 20 - 40 year plan towards the total eradication of the problem should be drawn and implemented through the implementation renewable energy policies among other measures. There is also the need to restructure the ailing Electricity Company of Ghana, to bring in private sector participation to install competition and efficiency.

The research findings indicated that, the cost of alternative power supply was high comparing with that of the electricity as a result additional cost incurred by the State in improving the grid power can be transferred to consumers [30]. In a situation where it becomes difficult to increase the quantity of electricity supply, quality improvement should be the best option.

The sharing of generators by the SMEs in a common vicinity is also encouraged to reduce the operational cost.

\section{Conclusion}

In conclusion, the power outages are having hasher effect on the activities of the SMEs. Hence pragmatic actions should be taken to implement the recommendations of this research to reduce the problems of these entrepreneurs so as to improve growth and reduce the demise rate of the businesses.

\section{References}

[1] Scott, A., Darko, E., Lemma, A. and Juan-Pablo, R. (2014) How Does Electricity Insecurity Affect Businesses in Low and Middle Income Countries? Shaping Policy for Development.

[2] ISSER (2015) Workshop on Electricity Insecurity and Its Impact on the Economy of Ghana. University of Ghana, Legon.

[3] Doe, F. and Asamoah, E.S. (2014) The Effect of Electric Power Fluctuations on the Profitability and Competitiveness of SMEs: A Study of SMEs within the Accra Business District of Ghana. Journal of Competitiveness, 6, 32-48. http://dx.doi.org/10.7441/joc.2014.03.03

[4] Fjose, C.A. and Grünfeld, L.S. (2010) SMEs and Growth in Sub-Saharan Africa, Identifying SME Roles and Obstacles to SME Growth. MENON-Publication No. 14/2010.

[5] Hatega, L. (2007) SME Development in Uganda. Private Sector Foundation Uganda, Kampala.

[6] Kauffmann, C. (2006) Financing SMEs in Africa, OECD Development Centre, Policy.

[7] IFC (2006) Small and Medium Enterprise Department, Background Note on Micro, Small and Medium Enterprise Database. Washington.

[8] OECD (2008) Review of Innovation Policies in China. OECD Publishing, Paris.

[9] Chau, V.S. (2009) Benchmarking Service Quality in UK Electricity Distribution Networks. Benchmarking: An International Journal, 16, 47-69. http://dx.doi.org/10.1108/14635770910936513

[10] Haanes, K., Balagopal, B., Arthur, D., Kong, M.T., Velken, I., Kruschwitz, N. and Hopkins, S.M. (2011) First Look: The Second Annual Sustainability and Innovation Survey. MIT Sloan Management Review, 52, 77-83.

[11] Beck, T. and Robert, C. (2014) Small- and Medium-Sized Enterprise Finance in Africa. Africa Growth Initiatives, Working Paper 16 July 2014.

[12] Adenikinju, A. (2005) Analysis of the Cost of Infrastructure Failures in a Developing Economy: The Case of the Electricity Sector in Nigeria. AERC Research Paper 148, African Economic Research Consortium, Nairobi.

[13] Rud, J.P. (2012) Electricity Provision and Industrial Development: Evidence from India. Journal of Development Economics, 97, 352-367. http://dx.doi.org/10.1016/j.jdeveco.2011.06.010

[14] Chissokho, L. and Seck, A. (2013) Electric Power Outages and the Productivity of Small and Medium Enterprises in Senegal, Investment Climate and Business Environment Research Fund (ICBE-RF). Research Report No. 77/13, Dakar.

[15] Isaksson, A. (2009) Energy Infrastructure and Industrial Development, Research and Statistics Branch, Programme Coordination and Field Operations Division. UNIDO, Vienna. 
[16] Legros, G., Rijal, K. and Seyedi, B. (2011) Decentralized Energy Access and the Millennium Development Goals: An Analysis of the Development Benefits of Micro-Hydropower in Rural Nepal.

[17] Association of Ghana Industries (2011) Business Barometer Report Is a Periodic Opinion Survey about What Chief Executives Make of the Business Environment. AGI, Ghana.

[18] Burlando, A. (2010) The Impact of Electricity on Work and Health: Evidence from a Blackout in Zanzibar.

[19] Mayer-Tasch, L., Mukherjee, M. and Reiche, K. (2013) Productive Use of Energy_PRODUSE: Measuring Impacts of Electrification on Small and Micro-Enterprises in Sub-Saharan Africa. https://www.esmap.org/sites/esmap.org/files/ESMAP_GIZ_BMZ_AEI_PRODUSE_Study_FullText_Optimized_0.pdf

[20] Moyo, B. (2012) Do Power Cuts Affect Productivity? A Case Study of Nigerian Manufacturing Firms. International Business \& Economics Research Journal, 11, 1163-1174.

[21] Escribano, A., Guasch, J.L. and Pena, J. (2009) Assessing the Impact of Infrastructure Constraints on Firm Productivity in Africa. World Bank, Washington DC.

[22] Kirubi, C., Jacobson, A., Kammen, D.M. and Mills, A. (2009) Community-Based Electric Micro-Grids Can Contribute to Rural Development: Evidence from Kenya. World Development, 73, 1208-1221. http://dx.doi.org/10.1016/j.worlddev.2008.11.005

[23] Cecelski, E. (2004) Re-Thinking Gender and Energy: Old and New Directions. Energia/EASE Discussion Paper.

[24] Akuru, U.B. and Okoro, O.I. (2011) Economic Implications of Constant Power Outages on SMEs in Nigeria.

[25] Tarun, B.K., Uddin, M.D.R. and Mondal, A. (2013) Impacts of Electricity Access to Rural SMEs. International Journal of Managing Value and Supply Chains, 4, 17-28.

[26] United Nations Industrial Development Organization, UNIDO (2009) Scaling up Renewable Energy in Africa. 12th Ordinary Session of Heads of State and Governments of the African Union (AU), January 2009, Addis Ababa.

[27] Abeberese, A.B. (2012) Electricity Cost and Firm Performance: Evidence from India, Department of Economics. Columbia University, New York.

[28] World Bank (2010) Review of Small Business Activities. World Bank, Washington, DC.

[29] Fisher-Vanden, K., Mansur, E. and Wang, Q. (2012) Costly Blackouts? Measuring Productivity and Environmental Effects of Electricity Shortages. NBER Working Papers 17741, National Bureau of Economic Research, Inc., Cambridge, MA.

[30] Steinbuks, J. and Foster, V. (2010) When Do Firms Generate? Evidence on In-House Electricity Supply in Africa. Energy Economics, 32, 505-514. http://dx.doi.org/10.1016/j.eneco.2009.10.012

[31] Attigah, B. and Mayer-Tasch, L. (2013) Productive Use of Energy (PRODUSE): The Impact of Electricity Access on Economic Development: A Literature Review. GIZ, Eschborn.

[32] Malik, A., Teal, F. and Baptist, S. (2006) The Performance of Nigerian Manufacturing Firms: Report on the Nigerian Manufacturing Enterprise Survey 2004. Centre for the Study of African Economies, Oxford.

[33] NBSSI (1990) Supporting Micro \&Small Scale Enterprises. A Handbook on Enterprise Development Part 1. NBSSI, Print Solutions, Accra. 


\section{Appendix}

\section{Research Questionnaires}

This research work is undertaking to have an insight on the effect of the current electricity power outages on the growth of SMEs (cold store operators) in the Asafo District of Kumasi in Ghana.

All information you provide will be treated as confidential and anonymous, and also will be used for academic research only. Thank you.

Please tick $(\sqrt{ })$ the most appropriate that describe your business since 2009 to date.

\begin{tabular}{|c|c|c|c|c|}
\hline 1. Strongly disagree & 2. Disagree & 3. Neither agree nor disagree & 4. Agree & \\
\hline
\end{tabular}

Power outages experience

$\begin{array}{lllll}1 & 2 & 3 & 4 & 5\end{array}$

1. I am aware of the power outages.

2. The power outages are not regular.

3. I do not get enough electricity supply for my business.

4. I have no idea when the outages will stop.

5. My business depends on electricity supply.

6. Intermittent power outages is killing my business.

\section{Operational cost}

6. Cost of materials has gone up.

7. Employee wages has up.

8. Cost of preserving my products has gone up.

9. Cost of utilities has gone up.

10. Maintenance and replacement cost has gone up.

11. High cost of power supply is negatively affecting my business.

\section{Alternative power supply}

12. Alternative power supply are not reliable.

13. Alternative power supply are not adequate and suitable substitute for my business.

14. Alternative power supply are expensive compare with that of electricity.

15. Generators are the most preferred substitute for electricity power.

16. The generators are not environmentally friendly.

SMEs growth (2009-2014)

17. I have reduced the number of my employees significantly.

18. Sales have been dropping drastically.

19. I have disposed of some of my assets.

20. I have closed down some branches.

21. I have reduced my product lines.

22. Most of my products perish frequently.

23. The customer base of the business has increased.

24. Existing customers have reduced their purchases. 


\section{General questions}

Please provide one answer to each of the following general questions on your business.

25. Gender? 1. Male 2. Female

26. What is the highest educational level of the owner or general manager of the business?

1: Less than high school diploma 2: High school diploma 3: A bachelor's degree

4: A master's degree or above $\quad$ 5: Others

27. Which of the following best describes your position in this business? Are you...

1: The sole owner of this business

2: A partner in this business

3: The person in charge of finance in this business

4: Occupying another position in this business

5: Others. Is your business...?

28. How long has your business been in existence?

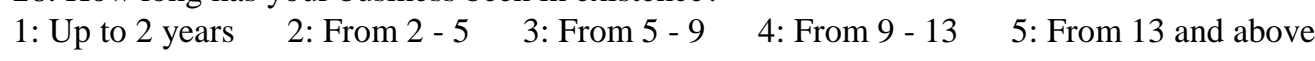

